\title{
Pulmonary mechanics and gas exchange characteristics in uncommon etiologies of acute respiratory distress syndrome
}

\author{
Richard H. Kallet ${ }^{1}$, Kelly Ho ${ }^{1}$, Michael S. Lipnick ${ }^{2}$, Michael A. Matthay ${ }^{3}$ \\ ${ }^{1}$ Respiratory Care Services, ${ }^{2}$ Critical Care Division, Department of Anesthesia and Perioperative Care, University of California San Francisco \\ at Zuckerberg San Francisco General Hospital and Trauma Center, San Francisco, CA, USA; ${ }^{3}$ Cardiovascular Research Institute, University of \\ California San Francisco, San Francisco, CA, USA \\ Contributions: (I) Conception and design: RH Kallet, MS Lipnick, MA Matthay; (II) Administrative support: None; (III) Provision of study materials \\ or patients: RH Kallet, K Ho, MS Lipnick; (IV) Collection and assembly of data: RH Kallet, K Ho; (V) Data analysis and interpretation: RH Kallet, \\ MS Lipnick, MA Matthay; (VI) Manuscript writing: All authors; (VII) Final approval of manuscript: All authors. \\ Correspondence to: Richard H. Kallet, MS, RRT, FAARC. Respiratory Care Services Bld-5:GA-2, Zuckerberg San Francisco General Hospital, 1001 \\ Potrero Ave., San Francisco, CA 94110, USA. Email: richkallet@gmail.com.
}

Background: Common causes of acute respiratory distress syndrome (ARDS) include pneumonia, aspiration, non-pulmonary sepsis and trauma. Little is known about pulmonary mechanics and gas exchange in less-common etiologies of ARDS, which comprises $12-23 \%$ of cases. Our hospital's ARDS quality assurance database contained a substantial number of these cases. This descriptive study examines the pulmonary mechanics, and gas exchange characteristics of this diverse cohort of ARDS subjects.

Methods: Between March 2010 and April 2017 we identified 94 subjects with less common etiologies of ARDS who had dead space fraction $\left(\mathrm{V}_{\mathrm{D}} / \mathrm{V}_{\mathrm{T}}\right)$ and respiratory system compliance $\left(\mathrm{C}_{\mathrm{RS}}\right)$ measured within 24 hours of ARDS onset; 86 of whom did not have sepsis as a co-diagnosis. There were 18 identifiable sources of ARDS. For descriptive purposes these were subsumed under 10 etiologic categories: pancreatitis $(n=16)$, hemorrhagic shock/reperfusion injury $(n=9)$, transfusion-associated acute lung injury (TRALI) $(n=3)$, drug overdose $(n=13)$, inhalation injury $(n=10)$, idiopathic $(n=10)$, neurogenic $(n=8)$, pulmonary toxicity $(n=3)$, hyper-immune response $(n=4)$, hepatic failure $(n=7)$, and 3 other cases: 2 cutaneous burns and one case of malaria. $\mathrm{V}_{\mathrm{D}} / \mathrm{V}_{\mathrm{T}}$ was measured using the Enghoff-Bohr equation. Arterial blood gases were drawn simultaneously with mixed expired $\mathrm{CO}_{2}$ using volumetric capnography and standard pulmonary mechanics measurements. Data are expressed as median (IQR). Comparisons between groups used Kruskal-Wallis and Dunn's post-tests, Mann-Whitney tests or Fisher exact tests.

Results: The majority of less common ARDS were from indirect sources (79\%) with $9 \%$ attributed to direct causes and $11 \%$ idiopathic. Because of the small sample sizes, there were no differences in pulmonary mechanics or gas exchange between subgroups classified as indirect, direct and idiopathic, or between subgroups sharing common lung injury mechanisms. Nevertheless, salient trends were apparent particularly in $\mathrm{C}_{\mathrm{RS}}$ and $\mathrm{V}_{\mathrm{D}} / \mathrm{V}_{\mathrm{T}}$. $\mathrm{C}_{\mathrm{RS}}$ was most severely reduced in the toxicity subgroup and least impaired in the idiopathic subgroup [18 (11 to 22$)$, and $40(30$ to 43$) \mathrm{mL} / \mathrm{cmH}_{2} \mathrm{O}$ respectively]. $\mathrm{V}_{\mathrm{D}} / \mathrm{V}_{\mathrm{T}}$ was extraordinarily high in the hepatic failure subgroup and lowest in pancreatitis [0.78 (0.57 to 0.79$)$ and 0.54 (0.47 to 0.65$)$ respectively]. There was less distinction in oxygenation as median values for all subgroups met moderate ARDS criteria. For the entire cohort, only $\mathrm{V}_{\mathrm{D}} / \mathrm{V}_{\mathrm{T}}$ was statistically different between non-survivors and survivors: $0.66(0.57$ to 0.78 ) vs. 0.59 (0.51 to 0.68 ), $\mathrm{P}=0.012$.

Conclusions: Within a diverse cohort having less common presentations of ARDS, there was apparent variability in the distribution of $C_{R S}, V_{D} / V_{T}$ compared to differences oxygenation dysfunction. Elevated pulmonary dead space still identified patients with higher mortality, as is the case with more common causes of ARDS.

Keywords: Acute respiratory distress syndrome (ARDS); pulmonary dead-space fraction; respiratory system compliance $\left(\mathrm{C}_{\mathrm{RS}}\right)$ 
Submitted Jan 23, 2018. Accepted for publication Jul 10, 2018.

doi: $10.21037 /$ jtd.2018.07.78

View this article at: http://dx.doi.org/10.21037/jtd.2018.07.78

\section{Introduction}

Acute respiratory distress syndrome (ARDS) can be triggered by a multitude of direct and indirect insults to the lungs. The most common triggers are pneumonia, aspiration, non-pulmonary sepsis and trauma (1). Although these etiologies are well described in the literature, relatively less attention has focused on uncommon causes of ARDS such as pancreatitis, hepatic failure, transfusionassociated acute lung injury (TRALI), reperfusion lung injury, and inhalational injury. These diverse causes of acute lung injury account for $12-23 \%$ of cases (2-4), thus making it difficult to accumulate enough information to conduct a meaningful description of the pathophysiology.

Recently, we reported less common etiologies were distinguished from trauma-associated ARDS by having higher physiologic dead-space fraction $\left(\mathrm{V}_{\mathrm{D}} / \mathrm{V}_{\mathrm{T}}\right)$ and oxygenation index $(\mathrm{OI})$, along with lower respiratory system compliance $\left(\mathrm{C}_{\mathrm{RS}}\right)$ and arterial oxygen tension-to-inspired oxygen fraction $\left(\mathrm{PaO}_{2} / \mathrm{FiO}_{2}\right)$ (4). Less common etiologies also were distinguished by having lower $\mathrm{V}_{\mathrm{D}} / \mathrm{V}_{\mathrm{T}}$ than those with aspiration-associated ARDS and higher OI than those with non-pulmonary sepsis (4).

Because we have recorded a relatively large number of subjects with less-common ARDS etiologies, we inquired whether similar patterns in pulmonary mechanics and gas exchange might be apparent within this catchall category. We hypothesized that, consistent with the main findings of our previous study, direct causes of lung injury would likely produce higher $\mathrm{V}_{\mathrm{D}} / \mathrm{V}_{\mathrm{T}}$ compared to indirect causes. We did not speculate whether $C_{R S}$ or oxygenation indices might differ between direct $v s$. indirect injury, nor between various etiologic subgroupings.

\section{Methods}

Briefly, as previously described (4), data were obtained from our hospital's quality assurance ARDS management database used to monitor our adoption of the National Institutes of Health's ARDS Clinical Trial's Network (ARDSNet) lungprotective ventilation protocol (5). Acute lung injury criteria based on the American-European Consensus Conference definition was used prospectively for entering subjects into the database (6). Because of the subsequent development of the Berlin definition all subjects were re-evaluated and redefined according to the newer ARDS definition (7). Use of our quality assurance data for research purposes was approved by the University of California, San Francisco's institutional review board for human subject protection with waiver of consent granted (IRB\#16-19189).

Routine $\mathrm{V}_{\mathrm{D}} / \mathrm{V}_{\mathrm{T}}$ measurements began in 2010 as part of implementing the ARDSNet protocol. Measurements were made within $12 \mathrm{~h}$ of protocol initiation with $94 \%$ of all measurements in the current study done on the day of ARDS onset, $4 \%$ within $24 \mathrm{~h}$ after ARDS onset and 2\% within 96h. $\mathrm{V}_{\mathrm{D}} / \mathrm{V}_{\mathrm{T}}$ was measured using the Enghoff-Bohr equation $\left[\mathrm{V}_{\mathrm{D}} / \mathrm{V}_{\mathrm{T}}=\left(\mathrm{PaCO}_{2}-\mathrm{PeCO}_{2}\right) \div \mathrm{PaCO}_{2}\right]$ whereby $\mathrm{PaCO}_{2}$ and $\mathrm{PeCO}_{2}$ are respectively the arterial and mixed expired carbon dioxide tensions (8). An arterial blood gas was drawn simultaneously with mixed expired $\mathrm{CO}_{2}$ measured by volumetric capnography (NICO monitor, Philips/Respironics, Wallingford, CT) as previously described (9).

Dead-space measurements coincided with a ventilatorsystems check including expired tidal volume $\left(\mathrm{V}_{\mathrm{T}}\right)$ both in $\mathrm{mL}$ and relative to predicted body weight according to the ARDSNet protocol (5), end-inspiratory plateau pressure (Pplat) and positive end-expiratory pressure (PEEP). Consistent with our previous studies $(4,9)$ assessments were made only when patients were observed to be calm and synchronous with the ventilator, in the absence of nursing care activities, and unless contraindicated, studied in the semi-recumbent position.

$\mathrm{C}_{\mathrm{RS}}$ was calculated as tidal volume $\left(\mathrm{V}_{\mathrm{T}}\right) \div$ (Pplat-PEEP) $(10)$. Measures of oxygenation function included the $\mathrm{PaO}_{2} /$ $\mathrm{FiO}_{2}$ ratio and $\mathrm{OI}$ which was calculated as the product of mean airway pressure and the percent of inspired oxygen divided by $\mathrm{PaO}_{2}$ (11). In addition, Lung Injury Score (LIS) (12), Simplified Acute Physiology Score II (SAPS II) (13) and Acute Physiology and Chronic Health Evaluation II (APACHE II) score (14) were calculated on the day of ARDS onset.

Of the 94 subjects identified with uncommon ARDS etiologies, 8 were excluded from the analysis because sepsis was a co-diagnosis. The 86 remaining subjects had 18 distinct etiologies, wherein only a minority of whom could be classified as direct (9\%), versus indirect injury (79\%) while 
Table 1 Classification grouping and etiologies of uncommon presentations of acute respiratory distress syndrome

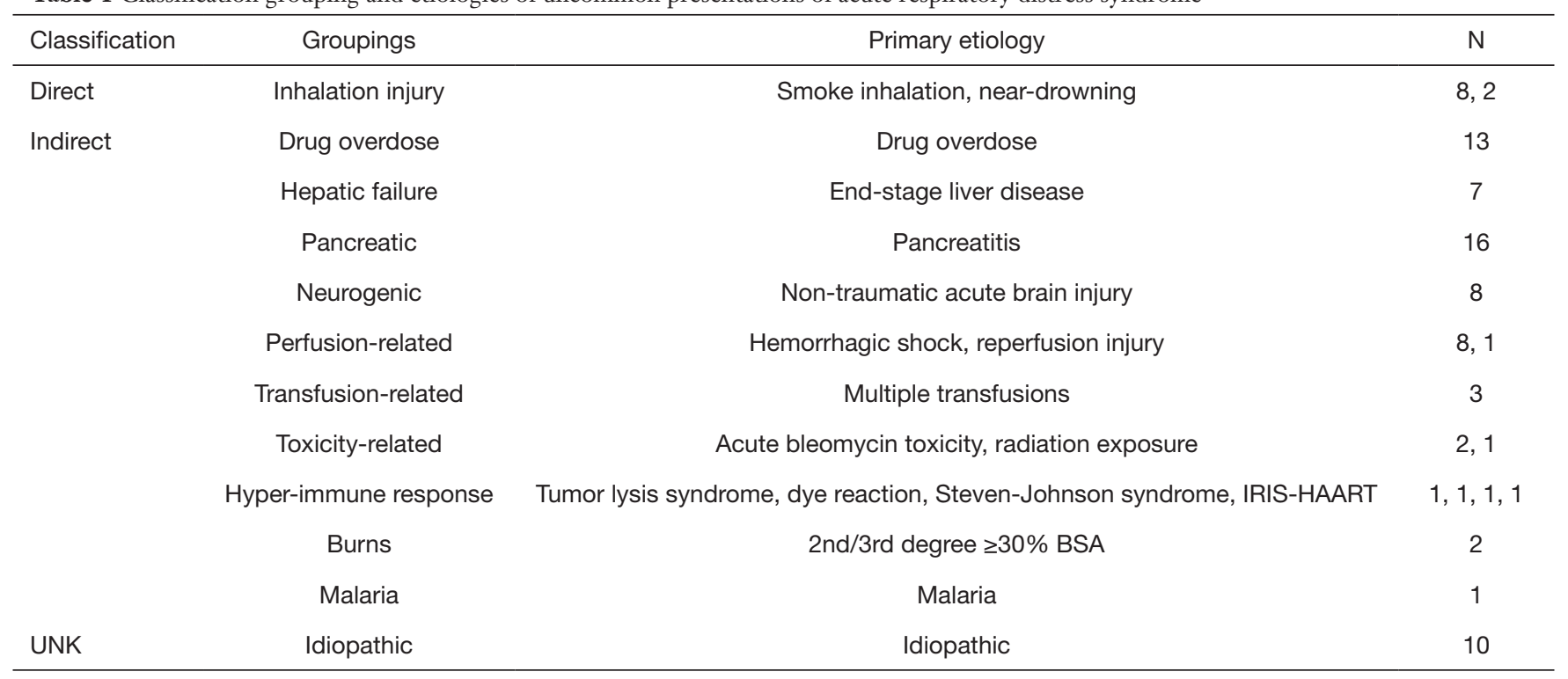

BSA, body surface area; IRIS-HAART, immune reconstitution inflammatory syndrome-highly active anti-retroviral therapy.

$11 \%$ had idiopathic causes (Table 1). When distinct etiologies shared what we believed were similar injury mechanisms we subsumed these into a larger group to analyze their mechanical and gas exchange characteristics. For example, near-drowning and inhalation injury were grouped together; as were those with apparent secondary lung injury from a hyperimmune response (e.g., tumor lysis syndrome, StevenJohnson Syndrome) In six of the 10 groups with eight or more subjects (inhalation injury, drug overdose, pancreatitis, hemorrhagic shock-reperfusion injury, neurologic injury and idiopathic) we also compared $\mathrm{C}_{\mathrm{RS}}, \mathrm{V}_{\mathrm{D}} / \mathrm{V}_{\mathrm{T}}, \mathrm{PaO}_{2} / \mathrm{FiO}_{2}$ and $\mathrm{OI}$ between survivors and non-survivors. Only the two cases of cutaneous burns and the single case of malaria could not be placed into a larger grouping.

Statistical analysis was done using PRISM (Graphpad Software, La Jolla CA). Given the small sample size and non-normal distribution, data are reported as median and interquartile range. Comparisons across groups were made using Kruskal-Wallis and Dunn's post-test. Comparisons between groups (i.e., non-survivors vs. survivors; indirect $v s$. direct injury) were made using Mann-Whitney tests. Categorical variables were assessed by Fisher Exact tests. Alpha was set at 0.05 .

\section{Results}

Because of the small sample size and wide dispersion of data our results were not statistically significant, the only exceptions were higher APACHE II score in subjects with ARDS associated with drug overdose versus pancreatitis (Table 2). When classified as either direct versus indirect lung injury no differences were found in $\mathrm{C}_{\mathrm{RS}}$ [33 (23 to 34) vs. 29 (21 to 38 ) $\mathrm{mL} / \mathrm{cmH}_{2} \mathrm{O}$ respectively, $\left.\mathrm{P}=0.24\right], \mathrm{V}_{\mathrm{D}} / \mathrm{V}_{\mathrm{T}}$ [0.66 ( 0.57 to 0.73 ) vs. 0.63 (0.53 to 0.70 ) respectively, $\mathrm{P}=0.39$ ], $\mathrm{PaO}_{2} / \mathrm{FiO}_{2}[115$ (83 to 123 ) vs. 113 (91 to 158 ) $\mathrm{mmHg}$ respectively, $\mathrm{P}=0.96]$, OI [14.8 (11.5 to 18.2) vs. 14.1 (9.3 to 21.4) respectively, $\mathrm{P}=0.51], \mathrm{pH}[7.29$ (7.25 to 7.33) vs. 7.34 (7.27 to 7.41) respectively, $\mathrm{P}=0.14]$ or Base Deficit [-6.0 (-7.9 to -5.4$)$ vs. -3.7 ( -8.2 to -0.2$) \mathrm{mEq} / \mathrm{dL}$ respectively, $\mathrm{P}=0.33$ ].

Analysis of subgroups based on similar injury mechanisms only produced apparent trends in terms of pulmonary mechanics and dead-space ventilation. The median $\mathrm{C}_{\mathrm{RS}}$ of our subjects ranged from 18 to $40 \mathrm{~mL} / \mathrm{cmH}_{2} \mathrm{O}$ (Table 3). Using the reported average $\mathrm{C}_{\mathrm{RS}}$ for ARDS $\left(30-34 \mathrm{cmH}_{2} \mathrm{O}\right)(10)$, six groups fell below this range whereas 3 groups were above. The lowest $C_{R S}$ was observed in toxicity, hyper-immune response and hepatic failure whereas the highest $C_{R S}$ was found in neurologic injury, drug overdose and idiopathic subgroups (Figure 1).

$\mathrm{V}_{\mathrm{D}} / \mathrm{V}_{\mathrm{T}}$, was extraordinarily high in ARDS associated with hepatic failure and lowest in pancreatitis (Table 4, Figure 2). All subgroups met moderate ARDS criteria based on median $\mathrm{PaO}_{2} / \mathrm{FiO}_{2}$ wherein eight of 10 groups had a median $\mathrm{PaO}_{2} / \mathrm{FiO}_{2}$ of 103 to $120 \mathrm{mmHg}$. The hyper-immune 
Table 2 Subject characteristics at onset of acute respiratory distress syndrome

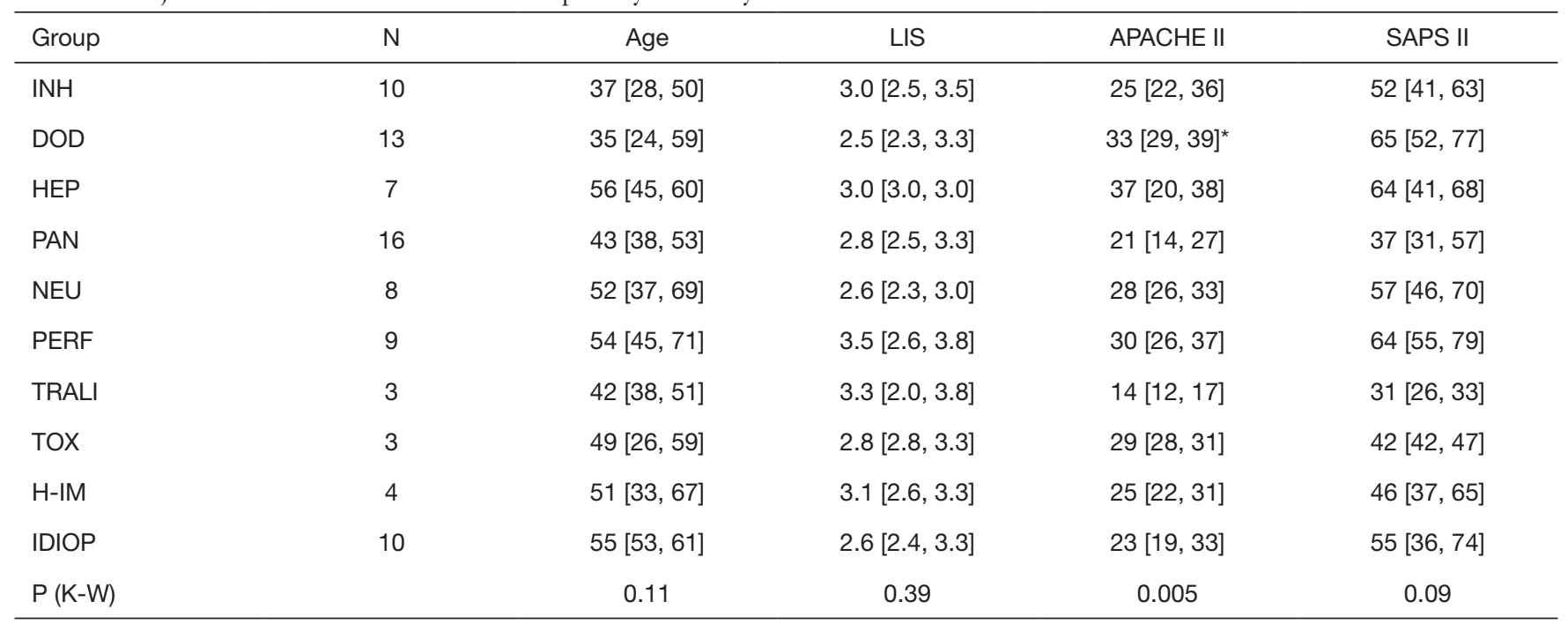

Data reported as median [25-75\% interquartile range]. K-W, Kruskal-Wallis test (Dunn's post-tests for $\mathrm{P}<0.05)$. ${ }^{*}, \mathrm{P}=0.03$ vs. pancreatitis. INH, inhalation injury; DOD, drug overdose; HEP, hepatic failure; PAN, pancreatitis; NEU, non-traumatic acute brain injury; PERF, perfusionrelated; TRALI, transfusion related acute lung injury; TOX, toxicity; H-IM, hyper-immune response; IDIO, idiopathic.

Table 3 Pulmonary mechanics at onset of acute respiratory distress syndrome

\begin{tabular}{|c|c|c|c|c|}
\hline Group & Pplat $\left(\mathrm{cmH}_{2} \mathrm{O}\right)$ & PEEP $\left(\mathrm{cmH}_{2} \mathrm{O}\right)$ & $\mathrm{V}_{\mathrm{T}}(\mathrm{mL} / \mathrm{Kg})$ & $\mathrm{C}_{\mathrm{RS}}\left(\mathrm{mL} / \mathrm{cmH}_{2} \mathrm{O}\right)$ \\
\hline DOD & $22[20,27]$ & $10[8,14]$ & $7.4[6.3,8.2]$ & $38[29,45]$ \\
\hline HEP & $23[22,29]$ & $10[8,10]$ & $6.2[5.9,6.5]$ & $23[19,29]$ \\
\hline PAN & $28[25,30]$ & $8[6,15]$ & $6.4[6.0,7.8]$ & $29[18,35]$ \\
\hline PERF & $28[24,33]$ & $13[8,16]$ & $6.2[5.6,7.8]$ & $25[19,29]$ \\
\hline TRALI & $27[26,29]$ & $12[5,16]$ & $6.2[5.8,8.4]$ & $26[23,29]$ \\
\hline TOX & $30[25,35]$ & $8[5,12]$ & $6.0[5.9,6.1]$ & $18[11,22]$ \\
\hline $\mathrm{H}-\mathrm{IM}$ & $28[21,33]$ & $12[10,14]$ & $6.9[5.1,10.9]$ & $22[21,36]$ \\
\hline
\end{tabular}

Data reported as median [25-75\% interquartile range]. K-W, Kruskal-Wallis test; INH, inhalation injury; DOD, drug overdose; HEP, hepatic failure; PAN, pancreatitis; NEU, non-traumatic acute brain injury; PERF, perfusion-related; TRALI, transfusion related acute lung injury; TOX, toxicity; H-IM, hyper-immune response; IDIO, idiopathic.

response and TRALI groups had median values of 154 and $163 \mathrm{mmHg}$ respectively. Acidosis was most pronounced in those with hepatic failure and hyper-immune response.

For the entire cohort, only $\mathrm{V}_{\mathrm{D}} / \mathrm{V}_{\mathrm{T}}$ was statistically different between non-survivors and survivors: $0.66(0.57$ to 0.78$) v s$. 0.59 (0.51 to 0.68$), \mathrm{P}=0.012$. Moreover, in the six subgroups with an $\mathrm{n} \geq 8$ subjects no consistent pattern emerged regarding differences between survivors and nonsurvivors for $\mathrm{C}_{\mathrm{RS}}, \mathrm{PaO}_{2} / \mathrm{FiO}_{2}$, OI, $\mathrm{pH}$ or $\mathrm{BD}$ (data not shown) Only $\mathrm{V}_{\mathrm{D}} / \mathrm{V}_{\mathrm{T}}$ demonstrated a consistent pattern of higher values among non-survivors (Figure 3).

For the three other cases, ARDS associated with 


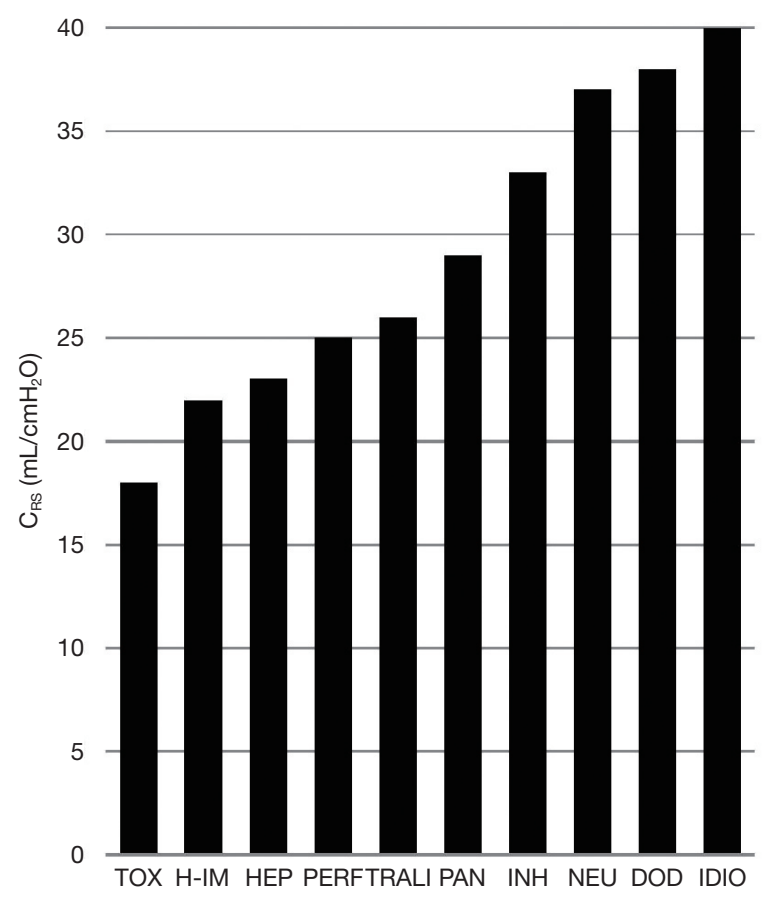

Figure 1 Differences in respiratory system compliance between different lung injury groupings. TOX, toxicity; H-IM, hyperimmune response; HEP, hepatic failure; PERF, perfusionrelated; TRALI, transfusion-associated acute lung injury; PAN, pancreatitis; INH, inhalation injury; NEU, neurologic injury; DOD, drug overdose; IDIO, idiopathic; CRS, respiratory system compliance. cutaneous burns (without inhalation injury) had the lowest $\mathrm{V}_{\mathrm{D}} / \mathrm{V}_{\mathrm{T}}(0.39)$ and highest $\mathrm{PaO}_{2} / \mathrm{FiO}_{2}(242 \mathrm{mmHg})$ along with a mid-range $\mathrm{C}_{\mathrm{RS}}\left(34 \mathrm{~mL} / \mathrm{cmH}_{2} \mathrm{O}\right)$ compared to the entire cohort. In contrast, the malaria case was characterized by both severely impaired gas exchange and chest mechanics $\left(\mathrm{V}_{\mathrm{D}} / \mathrm{V}_{\mathrm{T}}\right.$ : 0.68, $\mathrm{PaO}_{2} / \mathrm{FiO}_{2}: 73 \mathrm{mmHg}, \mathrm{C}_{\mathrm{RS}}: 25 \mathrm{~mL} / \mathrm{cmH}_{2} \mathrm{O}$ measured on PEEP of $14 \mathrm{~mL} / \mathrm{cmH}_{2} \mathrm{O}$ and $\mathrm{FiO}_{2}$ of 1 ).

\section{Discussion}

Our main finding was that subjects with uncommon ARDS etiologies are characterized primarily by indirect injury mechanisms; however, differences between these categories were not significant in regards to either chest mechanics or gas exchange. Yet, when the entire cohort was analyzed $\mathrm{V}_{\mathrm{D}} / \mathrm{V}_{\mathrm{T}}$ was the only pulmonary-specific variable associated with mortality.

Our main hypothesis that uncommon etiologies of ARDS from direct causes would have higher $\mathrm{V}_{\mathrm{D}} / \mathrm{V}_{\mathrm{T}}$ was not borne out by the data which demonstrated substantial diversity in the severity of carbon dioxide excretion dysfunction. In part this may have resulted from an imbalance between the two groups. However, our results suggest that even within the classification of indirect lung injury there appears to be marked variability greater than would be anticipated by its underlying mechanism (i.e., primary endothelial injury). For example, hepatic failure was associated with inordinately high

Table 4 Gas exchange and acid-base characteristics

\begin{tabular}{lccccc}
\hline Group & $\mathrm{VD} / \mathrm{VT}$ & $\mathrm{PaO}_{2} / \mathrm{FiO}_{2}(\mathrm{mmHg})$ & $\mathrm{OI}$ & $\mathrm{pH}$ & $\mathrm{BD}(\mathrm{mEq} / \mathrm{dL})$ \\
\hline INH & $0.66[0.55,0.75]$ & $116[79,146]$ & $14.4[11.4,29.8]$ & $7.31[7.26,7.35]$ & $-6.0[-7.7,-2.6]$ \\
DOD & $0.64[0.56,0.75]$ & $120[63,170]$ & $11.4[9.3,21.3]$ & $7.32[7.25,7.41]$ & $-6.5[-11.3,0.8]$ \\
HEP & $0.78[0.57,0.79]$ & $103[82,142]$ & $13[10,21.4]$ & $7.27[7.18,7.38]$ & $-8.7[-11.3,-2.6]$ \\
PAN & $0.54[0.47,0.65]$ & $109[82,138]$ & $15.4[10.1,22.7]$ & $7.34[7.27,7.43]$ & $-2.7[-7.4,0.7]$ \\
NEU & $0.68[0.47,0.73]$ & $109[98,147]$ & $15.6[8.4,20.4]$ & $7.34[7.19,7.43]$ & $-2.6[-8.0,0.5]$ \\
PERF & $0.63[0.49,0.66]$ & $103[70,146]$ & $20.5[9.4,36]$ & $7.39[7.32,7.46]$ & $-5.6[-7.3,2.2]$ \\
TRALI & $0.65[0.43,0.65]$ & $163[68,181]$ & $12.2[8.8,33.9]$ & $7.41[7.40,7.41]$ & $-1.1[-1.3,5.2]$ \\
TOX & $0.66[0.63,0.70]$ & $104[58,104]$ & $18.2[16.3,31.0]$ & $7.35[7.23,7.45]$ & $-1.3[-11.3,8.7]$ \\
H-IM & $0.64[0.55,0.79]$ & $154[111,194]$ & $12.9[8.7,13.8]$ & $7.28[7.17,7.28]$ & $-6.3[-7.4,-2.3]$ \\
IDIO & $0.61[0.48,0.69]$ & $118[76,175]$ & $16.1[6.9,26.1]$ & $7.36[7.32,7.41]$ & $-5.1[-8.9,3.3]$ \\
P (K-W) & 0.15 & 0.82 & 0.95 & 0.24 & 0.58 \\
\hline
\end{tabular}

Data reported as median [25-75\% interquartile range]. K-W, Kruskal-Wallis test; INH, inhalation injury; DOD, drug overdose; HEP, hepatic failure; PAN, pancreatitis; NEU, non-traumatic acute brain injury; PERF, perfusion-related; TRALI, transfusion related acute lung injury; TOX, toxicity; H-IM, hyper-immune response; IDIO, idiopathic. 


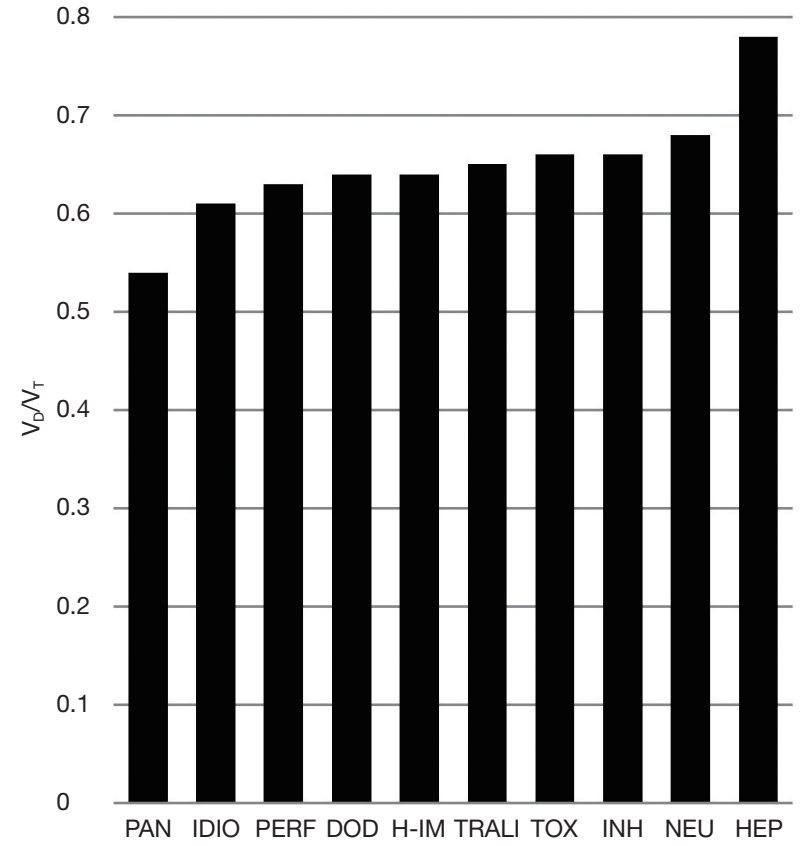

Figure 2 Dead-space fraction between and lung injury groupings. PAN, pancreatitis; IDIO, idiopathic; PERF, perfusion-related; DOD, drug overdose; H-IM, hyperimmune response; TRALI, transfusion-associated acute lung injury; TOX, toxicity; INH, inhalation injury; NEU, neurologic injury; HEP, hepatic failure.

$\mathrm{V}_{\mathrm{D}} / \mathrm{V}_{\mathrm{T}}$ while pancreatitis had the lowest $\mathrm{V}_{\mathrm{D}} / \mathrm{V}_{\mathrm{T}}$ similar to that in trauma-associated ARDS (4). This variability likely represents complex contributing mechanisms, as well as ambiguity in clinical presentation that are discussed below.

The tendency towards inordinately high $\mathrm{V}_{\mathrm{D}} / \mathrm{V}_{\mathrm{T}}$ in hepatic failure (compared to our subjects with direct lung injury) probably reflects the contribution of three factors: first, pulmonary arteriovenous shunting from the vasodilatory effects of elevated ammonia (15); second, the contribution of "shunt dead-space" (from ascitesinduced compression of dorsocaudal lung regions) (16); third, endothelial injury from disseminated intravascular coagulation documented in three cases (17). These subjects also had particularly low $\mathrm{C}_{\mathrm{RS}}$ in part from ascites, while the extraordinarily high mortality $(86 \%)$ is consistent with the established literature $(15,18)$. Although it is particularly difficult to exclude sepsis in those with hepatic failure, we noted that $\mathrm{V}_{\mathrm{D}} / \mathrm{V}_{\mathrm{T}}$ in our subjects $(0.78)$ was substantially higher than that reported in non-pulmonary sepsis (0.61) (4).

Likewise, acute pulmonary toxicity was characterized by higher $\mathrm{V}_{\mathrm{D}} / \mathrm{V}_{\mathrm{T}}$ similar to that reported in direct lung injury from inhalation injuries as well as pneumonia and

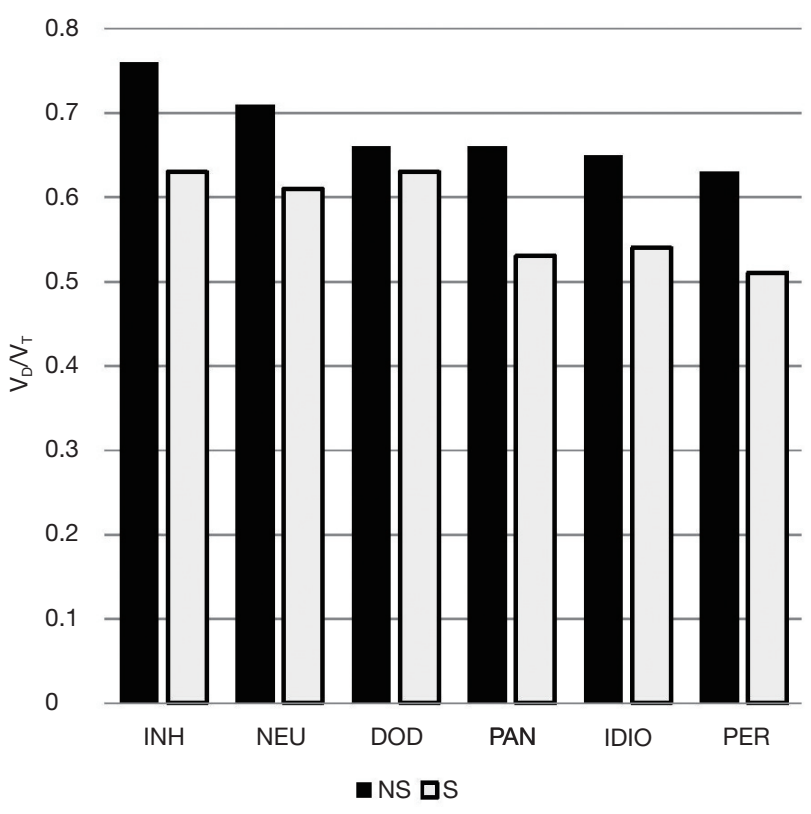

Figure 3 Differences in dead-space fraction among survivors(S) and non-survivors (NS) in the six largest acute lung injury subgroups. INH, inhalation injury; NEU, neurologic injury; DOD, drug overdose; PAN, pancreatitis; IDIO, idiopathic; PERF, perfusion-related.

aspiration (4), albeit from what appears to be indirect mechanisms. Bleomycin toxicity is an established model used in preclinical studies (19) that initially results in both microvascular endothelial injury and diffuse interstitial edema (that eventually injures the alveolar epithelium) $(19,20)$. The progressive cellular damage and resulting fibrosis from bleomycin toxicity is considered dissimilar from other forms of acute lung injury. Radiation-associated ARDS is similar to hyperoxic acute lung injury as it results in the generation of radical oxygen species that overwhelms the body's antioxidant defense mechanisms (21)

Our naming a hyper-immune associated ARDS subgroup was based upon other's hypotheses that this form of lung injury is caused by a proinflammatory mediator burst both during tumor lysis syndrome (22) and immune reconstitution inflammatory syndrome (23), whereas hypersensitivity or cell-mediated immune response may play a role in toxic epidermal necrolysis (24). Yet, in these presentations of ARDS, other occult mechanisms may be present. For example, toxic epidermal necrolysis often involves upper airway and bronchial mucosa injury increasing the possibility of aspiration or pneumonia.

Likewise, $V_{\mathrm{D}} / \mathrm{V}_{\mathrm{T}}$ in non-traumatic neurologic injury 
was similar to that recently reported in aspiration $(0.68)$ compared to subjects with isolated traumatic brain injury (0.55) (4). Therefore, the fact that aspiration was not witnessed in these subjects (nor suggested by inspection of tracheal aspirates following intubation) does not exclude the possibility that it might have occurred.

ARDS associated with acute pancreatitis was noteworthy for its similarity with trauma-associated ARDS, namely a tendency towards lower $\mathrm{V}_{\mathrm{D}} / \mathrm{V}_{\mathrm{T}}$ and mortality $(0.54$ and $19 \%$ respectively in our subjects). Acute lung injury in pancreatitis is believed to be caused by a two-hit mechanism: an initial pronounced systemic inflammatory response, followed by secondary injury from the systemic release of digestive enzymes that causes cell necrosis and damages pulmonary surfactant $(25,26)$.

Perfusion associated acute lung injury from hemorrhagic shock is complicated as all cases required initiation of our mass transfusion protocol These subjects likely suffered ischemia-reperfusion injury as well. Early studies of ARDS following hemorrhagic shock implicated coagulopathy as the primary mechanism (27) with fibrinogen degradation products such as fragment $\mathrm{D}$ directly implicated in the pathogenesis $(28,29)$. Additional pulmonary insults are associated with the sequelae of shock: most notably systemic inflammatory response due to macrophage activation from bacterial translocation occurring in the gut (30).

In addition, ischemia-reperfusion produces radical oxygen and nitrogen species causing injury both in directly affected organs as well as distant organs (31). The primary mechanism in TRALI appears to be neutrophil-mediated, along with a postulated "two-hit model" (i.e., a baseline proinflammatory state that activates the pulmonary endothelium followed by blood products that induce neutrophil activation (32). Interestingly, when comparing our subjects with hemorrhagic shock/reperfusion injury to the three cases of isolated TRALI both median $\mathrm{C}_{\mathrm{RS}}(25$ vs. $26 \mathrm{~mL} / \mathrm{cmH}_{2} \mathrm{O}$ respectively) and $\mathrm{V}_{\mathrm{D}} / \mathrm{V}_{\mathrm{T}}(0.63$ and 0.65$)$ were similar.

Despite considerable differences in pathophysiology between smoke inhalation and near drowning, there was very little difference in $\mathrm{C}_{\mathrm{RS}}\left(34\right.$ vs. $32 \mathrm{~mL} / \mathrm{cmH}_{2} \mathrm{O}$ respectively) and $\mathrm{V}_{\mathrm{D}} / \mathrm{V}_{\mathrm{T}}(0.65 \mathrm{vs}$. 0.63 respectively) between injury mechanisms. Smoke inhalation involves both thermal injury to the bronchial mucosa and toxic gas-induced injury to the alveolar capillary membrane, in addition to peripheral airway obstruction from fibrin clots. Pronounced increases in bronchial blood flow (approximately 8-fold) increases anatomic shunting and vascular engorgement (through bronchopulmonary anastomoses), whereas loss of barrier integrity causes hyperpermeability and surfactant deactivation (33). Our two cases of near-drowning involved both seawater and fresh water aspiration. In the former, hyperosmolarity, low temperature and high pathogen content of the aspirated fluid results in both an osmotic gradient across a damaged alveolar-capillary membrane and surfactant inactivation $(34,35)$. Freshwater aspiration is distinguished by less severe inflammatory mediator release and milder lung injury (36).

The obvious limitation of this study is that diverse, less common ARDS etiologies restricts the number of cases available for analysis. In consequence the ability to construct statistically meaningful, descriptions that advance our knowledge is stymied. In addition, from a pragmatic standpoint the infrequent occurrences make studying these etiologies impractical. Thus, our understanding of uncommon ARDS etiologies will remain speculative. This study was an initial attempt to explore this catch-all ARDS category and begin describing the apparent multiplicity of pulmonary mechanics and gas exchange derangements.

A further limitation is inter-observer variability and physiologic confounders that can affect measurement consistency when using data generated during routine clinical practice. For example, $\mathrm{C}_{\mathrm{RS}}$ is affected by the level of PEEP, $\mathrm{V}_{\mathrm{T}}$ size and fluid balance, none of which are controlled in a retrospective observational study such as ours. However, we found no correlation between $V_{\mathrm{T}}$ and $\mathrm{C}_{\mathrm{RS}}(\mathrm{r}=-0.07 ; \mathrm{P}=0.56)$ and only a weak correlation between PEEP and $\mathrm{C}_{R S}(\mathrm{r}=0.17 ; \mathrm{P}=0.12)$. Moreover, previous studies have shown a remarkable consistently in repeated measurements of $V_{D} / V_{T}$ and $C_{R S}$ over the first 3 days of ARDS with mean variability of approximately 0.02 and $1-2 \mathrm{~mL} / \mathrm{cmH}_{2} \mathrm{O}$ respectively (37-39).

\section{Conclusions}

In summary, this diverse sample of 86 subjects with less common presentations of ARDS exhibited marked variability in the distribution of $C_{R S}$ and $V_{D} / V_{T}$ between different etiologies. The relative rarity of these cases limited our findings to describing apparent differences between individual etiologies. In many instances this was made more ambiguous given the possibility of other mechanisms contributing to derangements in both pulmonary mechanics and gas exchange. Despite these limitations, elevated $V_{\mathrm{D}} / \mathrm{V}_{\mathrm{T}}$ was statistically higher in non-survivors compared to survivors. 


\section{Acknowledgements}

None.

\section{Footnote}

Conflicts of Interest: Mr. Kallet and Dr. Matthay have previous received research support from Philips/Respironics for prior studies involving volumetric capnography. The other authors have no conflicts of interest to declare.

Ethical Statement: Use of our quality assurance data for research purposes was approved by the University of California, San Francisco's institutional review board for human subject protection with waiver of consent granted (IRB\#16-19189).

\section{References}

1. Villar J. What is the acute respiratory distress syndrome? Respir Care 2011;56:1539-45.

2. Roupie E, Lepage E, Wysocki M, et al. Prevalence, etiologies and outcome of the acute respiratory distress syndrome among hypoxemic ventilated patients. Intensive Care Med 1999;25:920-9.

3. Manzano F, Yuste E, Colmenero M, et al. Incidence of acute respiratory distress syndrome and its relation to age. J Crit Care 2005;20:274-80.

4. Kallet RH, Zhuo H, Ho K, et al. Lung injury etiology and other factors influencing the relationship between dead-space fraction and mortality in ARDS. Respir Care 2017;62:1241-8.

5. Acute Respiratory Distress Syndrome Network, Brower RG, Matthay MA, et al. A trial of traditional tidal volume versus lower tidal volume ventilation in acute lung injury and acute respiratory distress syndrome. $\mathrm{N}$ Engl J Med 2000;342:1301-8.

6. Bernard GR, Artigas A, Brigham KL, et al. Report of the American-European consensus conference on acute respiratory distress syndrome: Definitions mechanisms, relevant outcomes, and clinical trials coordination. Am J Respir Crit Care Med 1994;149:818-24.

7. ARDS Definition Task Force, Ranieri VM, Rubenfeld GD, et al. Acute Respiratory Distress Syndrome: The Berlin Definition. JAMA 2012;307:2526-33.

8. Enghoff H. Volumen inefficax: Bemerkungen zur frage des schädlichen raumes. Upsala Lakareforen Forh 1938;44:191-218.
9. Kallet RH, Daniel B, Garcia O, et al. Accuracy of physiologic dead space measurements in patients with acute respiratory distress syndrome using volumetric capnography: Comparison with the metabolic monitor method. Respir Care 2005;50:462-7.

10. Kallet RH, Katz JA. Respiratory system mechanics in acute respiratory distress syndrome. Respir Care Clin N Am 2003;9:297-319.

11. Ortiz RM, Cilley RE, Bartlett RH. Extracorporeal membrane oxygenation in pediatric respiratory failure. Pediatr Clin North Am 1987;34:39-46.

12. Murray JF, Matthay MA, Luce JM, et al. An expanded definition of the adult respiratory distress syndrome. Am Rev Respir Dis 1988;138:720-3.

13. Le Gall JR, Lemeshow S, Saulnier F. A new Simplified Acute Physiology Score (SAPS II) based on a European-North American multicenter study. JAMA 1993;270:2957-63.

14. Knaus WA, Draper EA, Wagner DP, et al. Apache II. A severity of disease classification system. Crit Care Med 1985;13:818-29.

15. Siegel JH, Goldwyn RM, Farrell EJ, et al. Hyperdynamic states and the physiologic determinants of survival in patients with cirrhosis and portal hypertension. Arch Surg 1974;108:282-92.

16. Suter PM, Fairley HB, Isenberg MD. Optimum endexpiratory airway pressure in patients with acute pulmonary failure. N Engl J Med 1975;292:284-9.

17. Matuschak GM, Shaw BW. Adult respiratory distress syndrome associated with acute liver allograft rejection: resolution following hepatic retransplantation. Crit Care Med 1987;15:878-81.

18. Schwartz DB, Bone RC, Balk RA, et al. Hepatic dysfunction in adult respiratory distress syndrome. Chest 1989;95:871-5.

19. Matute-Bello G, Frevert CW, Martin TR. Animal models of acute lung injury. Am J Physiol Lung Cell Mol Physiol 2008;295:L379-99.

20. Adamson IY, Bowden DH. The pathogenesis of bleomycin-induced pulmonary fibrosis in mice. Am J Pathol 1974;77:185-97.

21. Kallet RH, Matthay MA. Hyperoxic acute lung injury. Respir Care 2013;58:123-41.

22. Marenco JP, Nervi A, White AC. ARDS associated with tumor lysis syndrome in a patient with Non-Hodgkin's Lymphoma. Chest 1998;113:550-2.

23. Sharma SK, Soneja M. HIV and immune reconstitution inflammatory syndrome. Indian J Med Res 
2011;134:866-77.

24. Timsit JF, Mion G, Rouyer N, et al. Bronchopulmonary distress associated with toxic epidermal necrolysis. Intensive Care Med 1992;18:42-4.

25. Pastor CM, Matthay MA, Frossard JL. Pancreatitisassociated acute lung injury. New insights. Chest 2003;124:2341-51.

26. Elder AS, Saccone GT, Dixon DL. Lung injury in acute pancreatitis: mechanisms underlying augmented secondary injury. Pancreatology 2012;12:49-56.

27. Blaisdell FW, Stallone RJ. The mechanism of pulmonary damage following traumatic shock. Surg Gynecol Obstet 1970;130:15-22.

28. Luterman A, Manwaring D, Curreri PW. The role of fibrinogen degradation products in the pathogenesis of the respiratory distress syndrome. Surgery 1977;82:703-9.

29. Manwaring D, Curreri PW. The role of platelet aggregation and release in fragment D-induced pulmonary dysfunction. Ann Surg 1980;192:103-7.

30. Angele MK, Schneider CP, Chaudry IH. Bench-to-bedside review: Latest results in hemorrhagic shock. Crit Care 2008;12:218.

31. Halladin NL. Oxidative and inflammatory biomarkers of ischemia and reperfusion injuries. Dan Med J 2015;62:B5054.

32. Alvarez P, Carrasco R, Romero-Dapueto C, et al. Transfusion-related acute lung injury (TRALI): current

Cite this article as: Kallet RH, Ho K, Lipnick MS, Matthay MA. Pulmonary mechanics and gas exchange characteristics in uncommon etiologies of acute respiratory distress syndrome. J Thorac Dis 2018;10(8):5030-5038. doi: 10.21037/ jtd.2018.07.78 concepts. Open Respir Med J 2015;9:92-6.

33. Enkhbaatar P, Traber DL. Patholphysiology of acute lung injury in combined burn and smoke inhalation injury. Clin Sci 2004;107:137-43.

34. Jin F, Li C. Seawater-drowning-induced acute lung injury: from molecular mechanisms to potential treatments. Exp Ther Med 2017:13:2591-8.

35. Folkesson HG, Kheradmand F, Matthay MA. The effect of salt water on alveolar epithelial barrier function. Am J Respir Crit Care Med 1994;150:1555-63.

36. Rui M, Duan YY, Zhang XH, et al. Differences between seawater- and freshwater-induced lung injuries. Zhongguo Wei Zhong Bing Ji Jiu Yi Xue 2009;21:416-20.

37. Kallet RH, Alonso JA, Pittet JP, et al. Prognostic value of the pulmonary dead-space fraction during the first six days of acute respiratory distress syndrome. Respir Care 2004;49:1008-14.

38. Kallet RH, Zhao H, Liu KD, et al. The association between physiologic dead-space fraction and mortality in patients with acute respiratory distress syndrome enrolled into prospective, multi-centered clinical trial. Respir Care 2014;59:1611-8.

39. Seeley EJ, McAuley DF, Eisner M, et al. Decreased respiratory system compliance on day 6 of mechanical ventilation is a predictor of death in patients with established acute lung injury. Respir Res 2011;12:52. 